\title{
IMPLEMENTING DIRECTED READING ACTIVITY (DRA) STRATEGY IN IMPROVING READING COMPREHENSION ABILITY
}

\author{
Sri Maladewi \\ SDN 009 Tembilahan Kota, Indragiri Hilir, Indonesia \\ srimaladewi68@gmail.com
}

\begin{abstract}
The purpose of this study was to improve students' reading comprehension ability through DRA strategy. This study was conducted by using classroom action research at grade I involving 28 students. The results of this study revealed that during the observation in Cycle I meeting I, teachers' activities was in low category with a score of 10 or $50.00 \%$. Then, the score increased to 12 or $60.00 \%$ in meeting II Cycle I with sufficient category. Moreover in Cycle II meeting I, the score of teacher's activity increased to 15 or $75.00 \%$ with good category, and in meeting II, again it increased 17 or $85.00 \%$ with very good category. In addition, this study also found that the students' reading comprehension ability before implementing DRA strategy was 39.29 with incomplete category. After implementing DRA strategy, the average score of classical completeness increased to 50 with incomplete category. After conducting the reflection on learning in cycle I, the results of students' completeness reached 79 with complete category even though it was not in accordance with the high target of improvement.
\end{abstract}

Keywords: DRA strategy, reading comprehension

\section{PENERAPAN STRATEGI DIRECTED READING ACTIVITY (DRA) DALAM MENINGKATKAN KEMAMPUAN MEMBACA PEMAHAMAN}

\begin{abstract}
ABSTRAK
Tujuan penelitian ini untuk meningkatkan kemampuan membaca pemahaman siswa dengan menggunakan strategi DRA dengan menggunakan metode penelitian tindakan kelas di kelas I dengan jumlah siswa 28 orang dengan hasil penelitian pada kegiatan observasi guru pada siklus I pertemuan I berkategori rendah dengan perolehan skor sebesar 10 atau 50.00\%. Pada pertemuan kedua siklus I mengalami peningkatan dengan perolehan skor sebesar 12 atau $60.00 \%$ dengan kategori cukup. Pada siklus II pertemuan I aktivitas guru mengalami peningkatan dengan perolehan skor 15 atau $75.00 \%$ dengan kategori baik, dan pada siklus II pertemuan II aktivitas guru mengalami peningkatan dengan perolehan skor sebesar 17 atau $85.00 \%$ dengan kategori sangat baik. Kemampuan membaca pemahaman siswa kelas II dengan menggunakan strategi DRA pada ketuntasan klasikal sebelum dilakukan Tindakan dengan rata-rata 39.29 dengan kategori tidak tuntas. Setelah dilakukan Tindakan dengan melakukan strategi DRA maka diperoleh rata-rata ketuntasan klasikal sebesar 50 dengan kategori tidak tuntas, setelah dilakukan refleksi pembelajaran pada siklus I diperbaiki kekurangan pada siklus II dengan hasil ketuntasan mencapai 79 dengan kategori tuntas walaupun tidak sesuai dengan target peningkatan yang tinggi.
\end{abstract}

Kata Kunci: strategi DRA, membaca pemahaman

\begin{tabular}{|c|c|c|}
\hline Submitted & Accepted & Published \\
\hline 20 Februari 2021 & 10 Maret 2021 & 25 Mei 2021 \\
\hline
\end{tabular}

\begin{tabular}{|l|l|l|l}
\hline Citation & $:$ & Maladewi, S. (2021). Implementing Directed Reading Activity (DRA) Strategy in Improving Reading Comprehension \\
& & $\begin{array}{l}\text { Ability. Jurnal PAJAR (Pendidikan dan Pengajaran), } \\
\text { http://dx.doi.org/10.33578/pjr.v5i3.8404. }\end{array}$ & $723-728$. \\
\hline
\end{tabular}

\section{PENDAHULUAN}

Membaca merupakan hal yang sangat penting bagi kehidupan seseorang karena dengan membaca kita dapat mengetahui segala hal. Banyak hal yang kita dapat dari membaca. Roger Fart (Zuchdi, dan Budiasih, 2001) mengemukakan bahwa "Reading is the Heart of Education". Roger menyatakan bahwa membaca itu merupakan jantung pendidikan. oleh karena itu, pengajaran membaca sangat perlu diajarkan pada anak - anak khususnya anak usia Sekolah Dasar. Membaca akan memberikan informasi- informasi penting yang dapat menjadi sarana untuk memperoleh kehidupan yang lebih baik disama yang akan datang (Kurniaman, Oktari, dan 
Pahrurazi, 2019). Jadi, tidaklah berlebihan jika pengajaran membaca perlu mendapatkan posisi yang sangat penting karena dengan membaca kita dapat mengakses informasi- informasi yang berguna, menambah wawasan dan pengetahuan baru yang akan semakin meningkatkan kecerdasannya sehingga mereka lebih mampu menjawab tantangan hidup dimasa mendatang.

Pemahaman membaca merupakan memahami operasi kognitif yang secara kompleks dalam keterampilan berbahasa yang akan diperoleh oleh siswa secara berbeda (Yamashita, $\&$ Shiotsu, 2015). Oleh karena itu di sekolah harus menerapkan strategi yang mampu menunjukan kritis dalam membaca sebagai alternatif cara membaca yang lebih dari pemrosesan informasi atau pribadi respon sebagai pendekatan. Artinya pembaca itu akan terlibat lebih dalam dengan teks dengan menganalisis, menafsirkan dan mengevaluasinya (Epstein dan Kernberger, 2006; Miri al., 2007; Taglieber, 2008; Fadhillah, 2017) maka penting diajarkan di sekolah tentang membaca pemahaman.

Kegiatan membaca merupakan salah satu keterampilan berbahasa, selain menyimak, bebicara, dan menulis. Pembaca yang memiliki pemahaman membaca yang baik menurut Westwood (Rahim, 2005) adalah “ seorang pembaca yang menggunakan berbagai keterampilan kognitif ketika mereka membaca. Di samping itu, pembaca juga menggunakan keterampilan metakognitif untuk memantau pemahaman mereka sendiri terhadap bacaan. Jadi dalam melakukan aktivitas membaca, kita tidak hanya memandang huruf- huruf atau kata - kata yang di rangkai alam sebuah bacaan, namun dalam aktivitas membaca tersebut pembaca harus dapat memahami dan berkomunikasi dengan penulis melalui tulisan yang dibaca oleh pembaca.Membaca merupakan keterkaitan antara aktivitas fisik dan mental. Secara fisik membaca memerlukan indera penglihatan dan secara mental memerlukan pemahaman dan daya ingat (Saidah, 2017). Dengan membaca mampu membangun pengetahuan (Kurniaman, dkk , 2018).

Menurut Rahim (2005:44) Strategi Directed Reading Activity (DRA) adalah suatu strategi yang digunakan untuk memperluas dan memperkuat kemampuan membaca siswa.Strategi ini dimaksudkan agar siswa mempunyai tujuan membaca yang jelas dengan menghubungkan berbagai pengetahuan yang telah di miliki oleh siswa sebelumnya untuk membangun pemahaman. Asumsinya, pemahaman bisa ditingkatkan dengan membangun latar belakang pengetahuan, menyusun tujuan khusus membaca, mendiskusikan, dan mengembangkan pemahaman sesudah membaca. Strategi Directed Reading Activity (DRA) mempunyai lima komponen sebagai berikut:

1. Motivasi dan pengembangan latar belakang. Guru berusaha membangkitkan minat membaca siswa pada suatu topik dengan membantu siswa menghubungkan mata pelajaran dengan pengalaman mereka sendiri atau dengan menggunakan alat peraga untuk membangkitkan minat pada pelajaran yang kurang akrab dengan siswa. Pada poin ini guru bisa menentukan apakah siswa mempunyai latar belakang pengalaman dan bahasa yang diperlukan untuk memahami cerita dan jika perlu anak mengembangkan konsep dan kosa kata baru sebelum mereka membaca cerita.

2. Membaca cerita secara langsung (dalam hati dan bersuara). Sebelum anak-anak membaca cerita dalam hati, guru menyediakan tujuan pertanyaan (atau suatu petunjuk belajar) atau menolong siswa menentukan tujuan mereka sendiri (dengan menanyakan atau memprediksi) untuk mengarahkan kegiatan membaca mereka. Kegiatan membaca berikutnya adalah membaca nyaring jawaban mereka, untuk pertanyaan tuntunan jawaban, membaca nyaring untuk membuktikan atau menolak prediksi mereka. Kegiatan berikutnya adalah membaca nyaring bahan bacaan, yaitu anak membaca cerita dengan nyaring sesuai dengan intonasinya.

3. Strategi atau kegiatan yang membangun keterampilan. Pada beberapa hal selama pelajaran berlangsung, guru menyediakan pengajaran langsung dalam satu atau lebih strategi atau keterampilan memahami.

4. Latihan tindak lanjut. Anak-anak melatih (mempraktekkan) strategi dan keterampilan 
yang telah dipelajari. Dalam kegiatan ini anakanak mengerjakan soal-soal latihan.

5. Kegiatan-kegiatan pengayaan. Dalam kegiatan ini dapat dilakukan kegiatan menghubungkan cerita dengan seni, misalnya seni drama.

DRA sebagai salah satu jenis strategi pembelajaran, dalam pelaksanaanya memiliki langkah-langkah pembelajaran. Langkah-langkah pembelajaran dilakukan untuk mewujudkan tujuan pembelajaran yang ingin dicapai. Langkahlangkah strategi pembelajaran Directed Reading Activity (DRA) yang diuraikan oleh Ennes dalam Rahim, (2005:44), terdiri dari:

1. Membentuk kelompok yang anggotanya 4-5 secara heterogen.

2. Guru memberikan wacana/ kliping sesuai dengan topik pembelajaran.

3. Membaca dalam hati wacana yang sudah disediakan oleh guru.

4. Guru memonitor siswa selama membaca dalam hati.

5. Siswa bekerja sama saling membacakan dan menanggapi isi materi bacaan/ide pokok dan ditulis dilembar kertas.

6. Mempresentasikan atau membacakan hasil kelompok

Guru membuat kesimpulan bersama dan memberikan penguatan terhadap tanggapan siswa dan memperluas gagasan-gagasan.

\section{METODE PENELITIAN}

Penelitian ini merupakan penelitian tindakan kelas (PTK). Penelitian tindakan kelas adalah suatu bentuk penelitian yang bersifat reflektif dengan melakukan tindakan-tindakan tertentu agar dapat memperbaiki dan atau meningkatkan praktik-praktik pembelajaran di kelas secara lebih profesional (Arikunto, 2008). Dari uraian di atas peneliti adalah suatu penelitian yang dilakukan oleh peneliti secara sistematis, reflektif terhadap aksi/ tindakan, untuk mengangkat masalah aktual yang dihadapi di lapangan dengan PTK guru mempunyai peran ganda yaitu: (a) sebagai praktisi; dan (b) sebagai peneliti. Maka tujuan dari PTK ini yaitu untuk memperbaiki dan mmeningkatkan kualitas praktik pembelajaran yang berkesinambungan sehingga meningkatkan hasil intruksional dan relevansi guru sehingga dihasilkan model pembelajaran yang efektif.

Subjek penelitian ini di kelas II SDN 009 Tembilahan Kota Kecamatan Tembilahan Kabupaten Indragiri Hilir dengan jumlah siswa laki-laki 15 orang dan perempuan 13 orang dengan total siswa 28 orang siswa dengan kemampuan yang berbeda. Teknik pengumpulan data menggunakan Teknik tes dan Teknik observasi dengan data yang sudah ada dianalisis dengan menggunakan skala sangat baik, baik, cukup, dan kurang untuk melihat ketuntasan belajar yang sudah diterapkan dengan menggunakan strategi DRA dalaam meningkatkan membaca pemahaman siswa kelas II sekolah dasar.

\section{HASIL DAN PEMBAHASAN}

Kegiatan penelitian ini dimulai terlebih dahulu guru mengucapkan salam dan meminta ketua kelas untuk memimpin doa, dan guru mengecek kehadiran siswa (absensi), pada hari ini semua siswa sebanyak 28 orang hadir dan siap untuk mengikuti pelajaran membaca yang dilaksanakan pada jam pertama. Guru melakukan apersepsi dengan memberikan pertanyaan seputar dongeng, seperti apakah siswa pernah membaca dongeng ? Dongeng apa saja yang pernah siswa baca?. Ternyata rata-rata seluruh siswa di kelas II ini sudah pernah membaca dongeng karena di halaman SDN 009 Tembilahan Kota ini banyak terdapat pojok literasi yang berisi buku dongengdongeng nusantara. Sehingga setiap siswa sudah mempunyai pengalaman membaca dongeng. Guru menyampaikan tujuan pembelajaran yaitu dengan menggunakan strategi directed reading activity pada pembelajaran membaca dongeng ini diharapkan siswa mampu untuk menyampaikan kembali isi dongeng dengan baik dan benar.

Kegiatan ini pelaksanaan dengan menggunakan strategi DRA terlebih dahulu guru membagikan teks dongeng 'kancil dan buaya' kepada setiap siswa, selanjutnya guru bertanya apakah ada siswa yang pernah membaca dongeng 'kancil dan buaya' ? Ternyata ada 2 orang siswa yang pernah membaca dongeng 'kancil dan buaya' selanjutnya guru menanyakan apakah kedua orang siswa tersebut ada yang masih mengingat isi cerita 
dongeng 'kancil dan buaya'. Namun dari ketiga siswa tersebut hanya mengingat garis besar dari isi dongeng tersebut. Kemudian guru meminta setiap siswa untuk membaca teks dongeng yang sudah dibagikan selama 10 menit. Selama siswa membaca dongeng di dalam hati guru membimbing dan mengawasi seluruh siswa membaca agar tetap tertib.

Setelah semua siswa selesai membaca dongeng, guru meminta siapa siswa yang berani tampil pertama kali ke depan untuk menceritakan tentang isi dongeng 'kancil dan buaya'. Siswa maju ke depan kelas dan menyampaikan isi dari dongeng 'kancil dan buaya'. Setelah semua siswa tampil ke depan untuk menyampaikan isi dari dongeng 'kancil dan buaya', guru meluruskan isi dan amanat dari dongeng tersebut secara lengkap.
Dan nilai apa saja yang harus dipelajari siswa dari dongeng tersebut. Kegiatan penutup dengan memberikan lembar evaluasi yang dikerjakan oleh setiap siswa secara individu dalam waktu 10 menit. Selama proses mengerjakan evaluasi, guru membimbing siswa yang menghadapi kendala menjawab soal-soal tersebut. Kemudian guru bersama siswa menyimpulkan pembelajaran hari ini tentang kemampuan siswa untuk menceritakan kembali isi cerita atau dongeng yang sebelumnya telah dibaca di dalam hati selama kurang lebih 10 menit. Selanjutnya guru memberitahukan bahwa pelajaran bahasa Indonesia selanjutnya akan mempelajari tentang menyampaikan isi dongeng 'semut dan kepompong' yang akan di ajarkan oleh guru. Hasil observasi aktivitas guru terlihat pada tabel 1 di bawah ini.

Tabel 1. Data Aktivitas Guru

\begin{tabular}{lcccc}
\hline \multirow{2}{*}{ Uraian } & \multicolumn{3}{c}{ Siklus I } & Siklus II \\
\cline { 2 - 5 } & Pertemuan I & Pertemuan II & Pertemuan I & Pertemuan II \\
\hline Jumlah skor & 10 & 12 & 15 & 17 \\
Persentase & $50.00 \%$ & $60.00 \%$ & 75.00 & 85.00 \\
Kategori & Kurang & Cukup & Baik & Sangat Baik \\
\hline
\end{tabular}

Berdasarkan tabel di atas, aktivitas guru pada siklus I pertemuan I berkategori rendah dengan perolehan skor sebesar 10 atau $50.00 \%$. Pada pertemuan kedua siklus I mengalami peningkatan dengan perolehan skor sebesar 12 atau $60.00 \%$ dengan kategori cukup. Pada siklus II pertemuan I aktivitas guru mengalami peningkatan dengan perolehan skor 15 atau $75.00 \%$ dengan kategori baik, dan pada siklus II pertemuan II aktivitas guru mengalami peningkatan dengan perolehan skor sebesar 17 atau $85.00 \%$ dengan kategori sangat baik. Dengan hasil kemampuan siswa dalam membaca pemahaman siswa dari UH I dan UH II mengalami peningkatan pada setiap siklusnya setelah dilakukan penerapan strategi DRA. Analisis membaca pemahaman ini memuat tentang pencapaian ketuntasan individu dan klasikal, perolehan data ketuntasan individu dan klasikal dapat dilihat pada tabel 2 di bawah ini.

Tabel 2. Hasil Kemampuan Membaca Pemahaman dan Ketuntasan Klasikal

\begin{tabular}{|c|c|c|c|c|c|}
\hline \multirow{3}{*}{$\begin{array}{c}\text { Hasil } \\
\text { Belajar }\end{array}$} & \multirow{3}{*}{$\begin{array}{c}\text { Jumlah } \\
\text { Siswa }\end{array}$} & \multirow{2}{*}{\multicolumn{2}{|c|}{$\begin{array}{l}\text { Ketuntasan } \\
\text { Individu }\end{array}$}} & \multirow{3}{*}{$\begin{array}{c}\text { Ketuntasan } \\
\text { Klasikal }\end{array}$} & \multirow{3}{*}{ Kategori } \\
\hline & & & & & \\
\hline & & Tuntas & Tidak Tuntas & & \\
\hline SD & \multirow{3}{*}{28} & 11 & 17 & 39.29 & Tidak Tuntas \\
\hline UH I & & 14 & 14 & 50 & Tidak Tuntas \\
\hline UH II & & 22 & 9 & 79 & Tuntas \\
\hline
\end{tabular}

Hasil dari tabel 2 di atas memberikan gambaran kemampuan membaca pemahaman siswa kelas II dengan menggunakan strategi DRA pada ketuntasan klasikal sebelum dilakukan
Tindakan dengan rata-rata 39.29 dengan kategori tidak tuntas. Setelah dilakukan Tindakan dengan melakukan strategi DRA maka diperoleh rata-rata ketuntasan klasikal sebesar 50 dengan kategori 
tidak tuntas, setelah dilakukan refleksi pembelajaran pada siklus I diperbaiki kekurangan pada siklus II dengan hasil ketuntasan mencapai 79 dengan kategori tuntas walaupun tidak sesuai dengan target peningkatan yang tinggi. Yang menjadi kendala dalam penerapan strategi ini karena pembelajaran secara daring yang mempersulit untuk mengatur siswa dalam mempersilahkan untuk membaca teknologi bisa juga memberi hambatan dalam proses pembelajaran apabila tidak didukung oleh fasilitas yang memadai (Kurniaman, dkk, 2020) perkembangan ilmu pengetahuan dan teknologi sudah membawa perubahan bagi semua aspek kehidupan manusia (Astiningtyas, 2018) masalahmasalah yang timbul oleh teknologi harus diselesaikan dengan memberikan fasilitas kepada manusia tentang teknologi juga. Membaca menjadi dasar dalam melek teknologi yang memang sangat dibutuhkan sebagai suatu keterampilan abad 21 (Noviana, Kurniaman, \& Huda, 2018) yang hamper semua sudah menggunakan teknologi.

\section{SIMPULAN DAN REKOMENDASI}

Pembelajaran menggunakan strategi DRA mampu meningkatkan pemahaman membaca apabila digunakan perencanaan yang lebih matang, apalagi pembelajaran daring yang membutuhkan perencanaan yang butuh persiapaan dari segi guru dan siswa dan adalagi kesiapan teknologi. Saran yang diberikan kepada guru untuk memberikan pelatihan terlebih dahulu kepada siswa dalam menggunakan teknologi serta mempersiapkan rancangan pembelajaran yang lebih matang.

\section{DAFTAR PUSTAKA}

Arikunto, S. (2008). Penelitian Tindakan Kelas. Bandung: Remaja Rosda Karya.

Astiningtyas, A. (2018). Kesiapan Guru Sekolah Dasar Dalam Pelaksanaan Pembelajaran Tematik Integratif Pada Kurikulum 2013. Primary: Jurnal Pendidikan Guru Sekolah Dasar, 7(1), 60-67.

Epstein, L. R., \& Kernberger, C. (2006). The Pocket Guide To Critical Thinking. Thomson/Wadsworth.
Noviana, E., Kurniaman, O., \& Huda, M. N. (2018). Pengembangan Aplikasi Bimbingan Tugas Akhir Mahasiswa Berbasis Website Pada Program Studi Pendidikan Guru Sekolah Dasar Fkip Universitas Riau. Primary: Jurnal Pendidikan Guru Sekolah Dasar, 7(1), 1-12.

Fadhillah, A. M. (2017). Embedding Critical Thinking Through Critical Reading: Teaching Narrative Text In Junior High School. Journal of English and Education, 5 (2), pp. 92 - 102. URL: http://ejournal.upi.edu/index.php/LE/article/view/9938.

Kurniaman, O., Oktari, C., \& Pahrurazi, P. (2019). The Implementation of Teaching Materials Reading Graphic Organizers in Elementary Schools. Lensa: Kajian Kebahasaan, Kesusastraan, dan Budaya, 9 (2), 105-119. DOI:

https://doi.org/10.26714/lensa.9.2.2019.105119.

Kurniaman, O., Noviana, E., Charlina, C., S. B. Simulyasih, N., Handayani, N. D., Sofyan, N. S., Zufriady, Z., Septyanti, E. (2018). Why Should Primary Teachers Develop Learning Material by Directed Reading Thinking Activity (DRTA) Strategy?: 4-D Model. Advanced Science Letters, 24(11), 83898391.

Kurniaman, O., Hidayat, M. L., Noviana, E., Munjiatun, M., \& Kurniawan, K. (2020). The Validation of LIAA (Linguistic Intelligence Assessment Android) Development In Elementary School. PPD Profesi Pendidikan Dasar, $\quad 7(2), \quad 162-170 . \quad$ DOI: 10.24036/blbs.v17i1.12696.

Miri, B., David, B., \& Uri, Z. (2007). Purposely Teaching for the Promotion of Higher-order Thinking Skills: A Case of Critical Thinking. Research in Science Education, 353-369 .

Rahim, F. (2005). Pengajaran Membaca di Sekolah Dasar. Jakarta: Bumi Aksara.

Saidah, H. (2017). Pengaruh Program Gemar Membaca terhadap Kemampuan Mengarang Siswa Kelas IV SD. Mimbar Sekolah Dasar, 4(3), 225-234.

http://doi.org/10.17509/mimbarsd.v4i3.7863. 
Taglieber, L. K. (2008). Critical Reading and Critical Thinking. Ilha do Desterro A Journal of English Language, Literatures in English and Cultural Studies.

Yamashita, J., \& Shiotsu, T. (2015).

Comprehension and Knowledge Components That Predict L2 Reading: A Latent-Trait Approach. Applied Linguistics, 2. 1-26. doi:10.1093/applin/amu079.

Zuchdi, D., dan Budiasih. (2001). Pendidikan Bahasa dan Sastra Indonesia di Kelas Rendah. Yogyakarta: PAS. 